\title{
A patologização da diversidade sexual: Homofobia no discurso de clínicos
}

The Pathologization of Sexual Diversity: Homophobia in clinicians' discourse

La pathologisation de la diversité sexuelle: Homophobie dans les discours

cliniques

\section{Gabriela Moita}

\section{(2) OpenEdition}

Journals

Edição electrónica

URL: http://journals.openedition.org/rccs/862

DOI: $10.4000 /$ rccs.862

ISSN: 2182-7435

Editora

Centro de Estudos Sociais da Universidade de Coimbra

Edição impressa

Data de publição: 1 Dezembro 2006

Paginação: 53-72

ISSN: 0254-1106

Refêrencia eletrónica

Gabriela Moita, « A patologização da diversidade sexual: Homofobia no discurso de clínicos », Revista Crítica de Ciências Sociais [Online], 76 | 2006, colocado online no dia 01 outubro 2012, criado a 19 abril 2019. URL : http://journals.openedition.org/rccs/862 ; DOI : 10.4000/rccs.862 


\section{GABRIELA MOITA}

\section{A patologização da diversidade sexual: Homofobia no discurso de clínicos}

Apresenta-se e analisa-se posicionamentos de técnicos de saúde mental disseminados por diversos modelos de leitura ainda ancorados no paradigma patológico da homossexualidade. O material exposto neste artigo é resultado de uma análise feita a discursos produzidos em grupos de discussão, organizados para efeitos de investigação, e formados quer por clínicos (psiquiatras e psicólogos), quer por gays e lésbicas que passaram por processos de acompanhamento terapêutico (por razões múltiplas e não apenas por questões ligadas à homossexualidade). Os níveis de homofobia e heterossexismo ainda existentes no contexto clínico português revelam quer a cumplicidade com modelos de formação não questionados, quer a dificuldade com que gays e lésbicas podem confrontar-se num processo que perpetua, senão mesmo amplia, a discriminação social de que são alvo.

Acreditai que a dignidade em que hão-de falar-vos tanto não é senão essa alegria que vem de estar-se vivo e sabendo que nenhuma vez alguém está menos vivo ou sofre ou morre para que um só de vós resista um pouco mais à morte que é de todos e virá

JorGE DE SENA, Carta a meus filhos sobre os fuzilamentos de Goya (1963)

No estamos legislando, Señorías, para gentes remotas y extrañas. Estamos ampliando las oportunidades de felicidad para nuestros vecinos, para nuestros compañeros de trabajo, para nuestros amigos y para nuestros familiares, y a la vez estamos construyendo un país más decente, porque una sociedad decente es aquella que no humilla a sus miembros. Una sociedad que ahorra sufrimiento inútil a sus miembros es una sociedad mejor.

Discurso de José Luís ZaPATERo, aquando da apresentação do Projecto-Lei de modificação do Código Civil, em 30 de Junho de 2005 


\section{Introdução}

O conhecimento sobre os mecanismos que regulam os processos de atracção entre os seres humanos não é dominado por nenhuma área específica do saber. No entanto, vários modelos de leitura do mundo, tanto religiosos, como científicos, têm validado e mantido um tipo de organização social, ao defenderem uma única forma de viver a afectividade ("moralmente adequada" ou "mais saudável", conforme o paradigma de onde emerge o discurso). Centrada numa moral religiosa, ou centrada numa moral de saúde, exige-se aos adultos envolvimento numa relação afectiva, heterossexual, preferencialmente com uma escolha única. Essa escolha, que prescreve uma definição de papéis rígida tanto para os homens como para as mulheres, recai numa prática em que a relação erótica é circunscrita ao coito vaginal que, por sua vez, tem como fundamento a reprodução.

Este conjunto de normas comportamentais exclui uma grande faixa da população: não serve a todas as etapas da vida, desvalorizando, por exemplo, a sexualidade nos idosos; não serve a pessoas com outros objectivos de vida - vida em comunidade por exemplo; não serve a pessoas com algumas dificuldades físicas e, finalmente, no que aqui diz respeito, não serve a pessoas com sentimentos e desejos diferentes daqueles que ali são prescritos.

Os mecanismos de regulação da norma, apoiados em múltiplas teorias produzidas, perfilhadas ora por éticas religiosas (que, no caso da Europa, culminariam nas práticas do Santo Ofício), ora pelo direito, ora pela medicina, ora pela estatística, foram permitindo que se matasse, prendesse, fizesse adoecer e discriminasse as pessoas que não cumpriam algumas daquelas regras. Recorde-se que ainda no século XIX se condenaram pessoas por práticas sexuais não coitais, no cumprimento de legislações então vigentes, como por exemplo a do Reino Unido; recorde-se que as mulheres inférteis foram e são ainda banidas de algumas comunidades; que o adultério, por parte da mulher, leva à lapidação em sociedades islâmicas; que o diagnóstico para as disfunções sexuais continua centrado na exigência de uma prática erótica que se vai construindo numa ditadura através da ética do direito ao prazer. Gays e lésbicas encontram-se entre os grupos mais fragilizados pela exclusão social e penalizados pela discriminação jurídica, médica e religiosa.

Para a promoção de uma sociedade mais justa, é fundamental denunciar e desmontar os modelos teóricos que perpetuam o modelo de exclusão e que foram sendo desenvolvidos dentro das diversas áreas disciplinares. 
Assim, se importa que o levantamento da homofobia ${ }^{1}$ seja feito em qualquer quadrante do tecido social, mais imperativo ele se torna entre os técnicos de saúde mental porquanto, no contexto clínico em que as pessoas se encontram em situação de vulnerabilidade, o impacto do papel do terapeuta pode ser ainda mais nocivo do que o de qualquer outro agente social, tal como o efeito do seu discurso pode ser multiplicador, se atendermos ao peso de que ele se reveste na opinião pública geral. ${ }^{2}$

Será aqui apresentado um levantamento de configurações homofóbicas que clínicos portugueses têm da sexualidade. Pretende-se, com a divulgação deste material, ajudar a aumentar a consciência dos processos de discriminação em que se é cúmplice - e falo tanto dos terapeutas que, muitas vezes, assimilam um conhecimento sem o questionar, como dos clientes, impossibilitados de se oporem a processos menos visíveis de opressão.

As configurações que se apresentam foram recortadas de discursos produzidos no contexto de grupos de discussão, ${ }^{3}$ um contexto que possui uma ampla validade inter-subjectiva e que permite colher atitudes, sentimentos, opiniões e percepções. Foram organizados grupos de discussão constituídos por clínicos e grupos de discussão constituídos por clientes gay e lésbicas (que alguma vez, por algum motivo, tivessem recorrido a apoio terapêutico).$^{4}$

\footnotetext{
${ }^{1}$ Embora tenha sido Kenneth Smith (1971) quem, pela primeira vez, usou o termo bomofobia, é habitualmente atribuída a George Weinberg (1972) a responsabilidade pela sua popularização. Weinberg definia, então, homofobia como o pavor em estar em espaços fechados com homossexuais. Mais tarde, em 1976, Gregory Lehne redefine o termo, passando bomofobia a significar um medo irracional ou intolerância relativamente à homossexualidade. Recentemente, Colleen Logan propõe, em alternativa, a expressão preconceito homossexual (bomoprejudice), baseando-se na definição de preconceito de Aronson, segundo o qual se trata de uma "atitude negativa ou hostil para com um grupo distinto de pessoas, baseado em generalizações resultantes de informação incorrecta ou incompleta" (Logan, 1996: 32).

${ }^{2}$ A comprová-lo, relativamente ao nosso país, refira-se como exemplo o facto público de, em entrevista à SIC, em 16/9/1995, o então primeiro-ministro António Guterres ter afirmado publicamente: "a homossexualidade não é um aspecto que me agrade particularmente" e ter remetido para a esposa, psiquiatra (como ele fez questão de realçar), a resposta à pergunta que lhe era colocada sobre o seu entendimento da homossexualidade (Público, 1995, 17 de Set.). Lembre-se ainda que, a propósito de um texto emitido em Diário da República a 6 de Janeiro de 1999, onde se definia a Classificação Nacional das Deficiências e se integrava a homossexualidade como deficiência da função heterossexual, a instância a que os movimentos de defesa dos direitos dos homossexuais portugueses recorreram a pedir apoio para questionar esta decisão foi exactamente a Ordem dos Médicos, que imediatamente pediu parecer ao Colégio de Psiquiatria (Público, 1999, 16 de Fev.). Os três psiquiatras nomeados foram unânimes em considerar que a homossexualidade não "é doença" nem "deficiência" nem "patologia, quer psicológica, quer física" (Público, 1999, 18 de Fev.).

${ }^{3}$ A pesquisa sobre a homofobia em contexto clínico, de que aqui se expõem alguns elementos, foi apresentada em 2001, na dissertação de doutoramento Discursos sobre a bomossexualidade no contexto clínico. A homossexualidade de dois lados do espelho (Moita, 2001).

${ }^{4}$ A proposta de escutar os intervenientes no processo terapêutico - clínicos e clientes - satisfaz os requisitos do processo conhecido por triangulação, uma das estratégias defendidas por vários
} 
Como o objectivo do estudo não foi investigar os discursos que se repetem, mas obter a maior variabilidade discursiva possível e identificar diferenças, tornou-se mais relevante para a selecção dos participantes um critério de pertinência do que um critério de extensão, de forma a satisfazer a saturação $0^{5}$ da informação por representatividade.

Foram organizados cinco grupos de discussão constituídos por clínicos, e três grupos de discussão constituídos por clientes. ${ }^{6}$ Relativamente aos grupos de clínicos, o critério de heterogeneidade intra-grupos utilizado (por forma a provocar diferenças e contradições) foi a idade (com amplitudes por grupo de 10, 11, 20, 20 e 40 anos) e a formação teórica dos participantes (psicanalítica, comportamental, sistémica, biológica). O sexo dos elementos participantes foi o critério de heterogeneidade entre grupos. Pressupôs-se, a partir da bibliografia consultada, que ambos os critérios poderiam ser lugar de uma produção de discursos distintos. Assim, foram constituídos um grupo de terapeutas masculinos, um grupo de terapeutas femininas e três grupos mistos de clínicos. As reuniões ocorreram na Figueira da Foz (no contexto de um congresso de Psicodrama), em Coimbra e em Lisboa.

Para os grupos de clientes, definiu-se como critérios de heterogeneidade intra-grupos o facto de todos terem finalizado o processo terapêutico, de estarem ainda em terapia e a idade; teve-se, além disso, o cuidado de se escolher pessoas que tivessem tido apoio terapêutico em momentos diferentes no tempo. O critério de heterogeneidade entre grupos foi também o sexo. Organizou-se um total de três grupos: um grupo de mulheres, um grupo de homens e um grupo misto. As reuniões tiveram lugar em Lisboa e no Porto. Em cada uma delas participaram entre cinco e oito pessoas. ${ }^{7}$ A duração aproximada do encontro foi de hora e meia a duas horas. As reuniões foram gravadas em cassetes audio e posteriormente transcritas integralmente para papel, fornecendo a transcrição o corpus para a análise posterior.

autores para procurar fornecer mais riqueza de informação (Hill et al., 1997; Stiles, 1993). Esta estratégia aumenta a coerência dos resultados e a sua validade através de um processo de convergência, embora possam ser esperados diferentes resultados de cada perspectiva.

${ }_{5}$ A saturação teórica alcança-se "quando a análise adicional já não contribui para a descoberta de nada novo sobre uma categoria” (Valles, 1997: 356).

${ }^{6}$ Uma vez que "dois grupos de composição semelhante discutindo sobre o mesmo tema produzem um discurso monótono e redundante" (Ibañez ,1992: 280), determinadas as composições dos grupos que pareceram convenientes, bastou um grupo ou dois para cada composição, de forma a que a informação fosse completa para a compreensão do fenómeno.

$7 \mathrm{~A}$ importância do tamanho do grupo deve-se às diferenças de interacção que se criam. Grupos com mais de doze elementos são contra-indicados, devido à tendência para a formação de subgrupos. Por outro lado, mini-grupos (de três a cinco participantes) proporcionam um leque mais fechado de informação e exigem de cada membro mais participação (Kruger, 1988). 
Foram utilizadas distintas formas de recrutamento dos participantes nos grupos, embora a mais comum tenha sido o recurso a elementos-ponte (Ibañez, 1992), ${ }^{8}$ ou seja, os elementos escolhidos para recrutar os participantes nos grupos foram quer sujeitos pertencentes a redes pessoais (de trabalho, de amizade), quer organizações de defesa dos direitos de homossexuais, a quem se pediu indicação de pessoas com características específicas da classe de actuantes (Ibañez, 1992) de cada um dos grupos. Excepção a esta modalidade foi a selecção dos participantes nos grupos de clínicos realizados na Figueira da Foz, durante um congresso de Psicodrama: estes grupos foram organizados a partir de um contacto prévio com todos os congressistas, a quem se enviou uma carta por correio, auscultando a disponibilidade de participar no estudo, mediante o preenchimento do questionário que seguia em anexo e cujos dados permitiram a selecção e a posterior constituição dos grupos.

O pedido feito aos elementos-ponte para a selecção dos participantes nos grupos dos clientes foi o de indicação de pessoas homossexuais, com as características do grupo a integrar, que alguma vez tivessem recorrido ao apoio de um técnico de saúde mental (psiquiatra ou psicólogo), independentemente do motivo. Desta forma, o critério da homossexualidade dos participantes foi num momento inicial definido pelos elementos-ponte.

Cada sessão foi iniciada com a introdução do tema, ficando de seguida entregue ao grupo a orientação a assumir, bem como a construção do espaço de resposta, os temas a desenvolver e a ordem dos mesmos. Pontualmente, foram devolvidos alguns temas, com o objectivo ou de desenvolver aspectos que se relacionavam com as preocupações da investigação ou de evitar distanciamentos com descrições excessivamente pormenorizadas, ou aparentemente irrelevantes.

Aos clínicos foi pedido que falassem dos clientes homossexuais, referindo o que entendessem dever salientar, desfocalizando-se desta forma a atenção sobre eles próprios. Aos clientes foi proposto que comentassem a experiência terapêutica de cada um, de forma a desfocalizarem a atenção, neste caso, dos clínicos. O sentido de uma ligeira desfocalização do tema foi facilitar a espontaneidade do diálogo e diminuir possíveis resistências. Pediu-se licença para gravar, com o objectivo de facilitar o trabalho posterior, garantindo-se o anonimato dos testemunhos.

No final das sessões, foi passado um questionário anónimo de levantamento de dados sócio-demográficos, com o objectivo de melhor caracterizar os elementos constituintes dos grupos.

\footnotetext{
${ }^{8}$ A tarefa dos elementos-ponte implicou vários procedimentos: desde a identificação ao contacto e à avaliação da possível disponibilidade, até ao assegurar a presença no dia da reunião, mantendo-me em permanente informação.
} 
O questionário aplicado aos clínicos foi elaborado com base no questionário utilizado por Garnets et al. (1991) quando, em 1986, no contexto da American Psychological Association, investigaram as tendências em psicoterapia com clientes gay e lésbicas. É constituído pelos seguintes campos: sexo, idade, formação académica, grau académico e ano em que foi obtido, anos de prática clínica, informação sobre pós-graduações e modelos de referência ${ }^{9}$ e, por fim, o número de clientes homossexuais, masculinos e femininos que foram seguidos.

O questionário aplicado aos clientes foi construído com base nos questionários aplicados por Liddle (1996, 1997), nos seus estudos sobre terapia com gays e lésbicas, nomeadamente sobre a relação entre a orientação sexual, o sexo, as práticas de aconselhamento, o nível de satisfação referido e a importância do processo de selecção dos terapeutas no nível de satisfação com a terapia. Os campos que integram o questionário são os seguintes: idade, profissão, grau de escolaridade, número de terapeutas procurados e respectivo sexo, bem como o número de consultas, a data em que foi recebido apoio terapêutico pela última vez e os motivos de procura de apoio. No caso específico da determinação da orientação sexual, variável apenas analisada nos grupos de clientes, foi pedida a auto-identificação e pedido também que se situassem na escala de Kinsey. ${ }^{10}$ Para evitar a etiqueta "homossexual", rótulo por vezes difícil de admitir em fases iniciais do processo de desenvolvimento da identidade homossexual, substituiu-se, no caso dos sujeitos do sexo masculino, o termo "heterossexual" por "mulheres" e "homossexual" por "homens", e no caso dos sujeitos do sexo feminino, "heterossexual" por "homens" e "homossexual" por "mulheres".

Finalizados os grupos, a etapa seguinte foi transcrever para papel a gravação das falas produzidas na discussão, identificando e registando silêncios, interrupções, repetições, que pudessem ser devidamente descodificados e passíveis de uma atribuição de sentido, no contexto da situação de grupo. A discussão de cada grupo resultou, em média, em cerca de 50 páginas dactilografadas. Concluída a transcrição, a etapa seguinte foi fazer uma análise de conteúdo, por referência às questões da investigação, aos dados de outras investigações e às surpresas do texto.

\footnotetext{
${ }_{9}$ Embora o modelo teórico de referência tivesse sido um critério de recrutamento, decidiu-se integrar esta informação no questionário, quer para perceber a relação do modelo dominante com outros modelos, quer para se obter a autodefinição.

${ }_{10}$ Apesar da existência de vários modelos para a avaliação da orientação sexual (Coleman, 1988; Klein, Sepekoff e Wolff, 1985), optou-se pelo modelo de Kinsey, à semelhança do que aconteceu noutras investigações (Cass, 1984; Rubio, 1996).
} 
Embora na análise feita aos discursos produzidos se tenham observado configurações da sexualidade que podem ser enquadradas em modelos inscritos num paradigma social, como é o caso do modelo afirmativo gay ${ }^{11}$, do construcionismo social e da teoria queer, o que aqui se expõe é uma síntese das configurações homofóbicas, defendidas por diversos modelos de leitura inscritos no paradigma que patologiza a afectividade homo-erótica.

\section{A patologização de uma expressão da sexualidade}

\subsection{Definindo a homossexualidade}

$\mathrm{Da}$ análise dos discursos produzidos destaque-se o facto de existirem em Portugal clínicos que interpretam negativamente a homossexualidade: ou verbalizando-a explicitamente como "défice" ou "falha" ("é uma parafilia", "é um desvio sexual”, "é uma disfunção"; "é um processo anómalo de comportamento [...], como muitos outros tipos de comportamento, como a impotência”) ou considerando-a, do ponto de vista moral, como um comportamento "contra-natura" ou ainda comentando-a subterraneamente, através de afirmações dúbias, de movimentos discursivos de ambiguidade, ou mesmo de leituras bizarras, como aquela que considera a homossexualidade "uma forma de afirmação", "um processo de fazer um movimento de promoção" ou "um certo tipo de desporto radical”. Por vezes, a atribuição de um carácter negativo à orientação homossexual não seria nunca reconhecida pelos terapeutas. É pelo nosso olhar e pelo olhar dos clientes que esta imagem é devolvida. A exemplificar esta afirmação observe-se a tentativa de procura de causas:

mas sobretudo o que [o terapeuta] queria saber era a relação com o meu pai, com o meu irmão, muito a tentar saber se havia ali qualquer problema, qualquer coisa [...] procurou não fazer juízos, procurou foi que eu analisasse um bocado

só houve uma parte, já quase no fim das sessões, em que [a terapeuta perguntou] como é que era a minha infância... se foi isolada, se convivia mais com rapazes [ou com] raparigas e aí é que fiquei assim um bocado [...] "será que tens um bocadinho de preconceito ao fazeres-me essa pergunta?"

\footnotetext{
${ }^{11} \mathrm{O}$ modelo de terapia afirmativa gay constitui, na realidade, não um modelo teórico, mas um conjunto de princípios que deverão orientar a prática terapêutica com clientes homossexuais, particularmente com aqueles que apresentam dificuldades relativas à sua homossexualidade. Em vez de diagnosticar, de tentar determinar os factores causais e de tentar a mudança da orientação sexual, o objectivo do terapeuta que partilha esta perspectiva é ajudar os clientes a aceitarem a sua orientação sexual.
} 
A análise da etiologia de um comportamento não implica necessariamente uma visão negativa ou deficitária desse comportamento, no entanto, enquanto as causas da heterossexualidade não forem um elemento de análise clínica haverá sempre uma diferença no valor atribuído a cada vivência. É neste enquadramento que a tentativa de encontrar explicações para a homossexualidade pode transmitir ao cliente a mensagem de que a homossexualidade é patológica. O cliente, por seu turno, instigado a apresentar a sua história e, simultaneamente, porque influenciado pelas teorias mais popularizadas sobre a etiologia da homossexualidade, torna-se, inconscientemente, cúmplice do posicionamento do terapeuta, segundo o qual a homossexualidade é uma doença ou o resultado de um desenvolvimento desadequado (McHenry e Johnson, 1993).

Refira-se ainda que, no caso de alguns clínicos, as posições de indiferença em relação às sexualidades chegaram mesmo a ser contraditas, à medida que a discussão se foi aprofundando. A título de exemplo, vale a pena assistir à sequência das falas de um clínico, que parte de uma posição de indiferença para, no final, assumir claramente o seu preconceito ao considerar que a homossexualidade é "uma falha":

[Um cliente] pôs uma questão curiosa logo de entrada. Logo na primeira consulta perguntou-me "eu quero saber o que é que pensa disto da homossexualidade. Eu sou gay". Portanto, obrigou-me a definir-me face [à homossexualidade] e em termos pessoais. Eu achei por bem definir-me em termos pessoais e clarifiquei que não era aderente, mas que não tinha nada nem contra nem a favor, que não era uma questão que me incomodasse

Quer dizer, não me venham com a treta de dizer que a homossexualidade é uma normalidade! não consigo concebê-la dessa forma, face a isso como em relação a muitas outras patologias enfim, há uma parte de mim que deseja sempre [que seja heterossexual]... Quando eu vejo um gajo a descompensar, eu também, no mínimo, desejo que ele não descompense, [...] há uma parte de mim enorme que deseja que ele não descompense e acho que a questão que ponho em relação à homossexualidade é a mesma. Quem me dera que o tipo não fosse psicótico.

Quer dizer, mas eu tenho um preconceito, tenho um preconceito que é: "por alguma razão ele tem uma pila! Não?"

Eu não consigo entrar no "isto aqui é tudo normal”, não! Há uma área que não funciona, há uma área que não funciona, pode é ser menos ou mais perturbador, não é? Mas não consigo pôr-me na posição de dizer "está tudo bem, é homossexual 
e está tudo bem”, não, “se é homossexual, algo não está bem”. É a posição básica em que eu me sinto.

Há sempre uma falha, uma falha narcísica, claro!

Se a procura das causas de um comportamento não implica necessariamente uma visão negativa ou deficitária desse comportamento, uma interpretação do comportamento como patológica leva obrigatoriamente à análise da sua etiologia. A discussão entre os participantes nos grupos de discussão sobre as causas da homossexualidade manteve-se, tal como em finais do século passado, em torno da dicotomia inato/adquirido, sendo defendidas posições que a entendem como resultado de factores psicológicos - causas relacionais e factores de aprendizagem - de factores biológicos, ou ainda de causas multifactoriais, sempre insistindo na dimensão patológica da homossexualidade.

\section{2. Explicando a homossexualidade: Teses etiológicas}

\subsubsection{Transgressão dos papéis de género dos modelos de identificação}

Dentro do paradigma patológico a abordagem psicanalítica foi a que surgiu articulada de uma forma mais clara, tendo sido explicitamente referida por um terapeuta a constelação familiar de uma mãe possessiva e/ou um pai ausente como responsável pelo desenvolvimento da homossexualidade: ${ }^{12}$

[O desenvolvimento da homossexualidade] tem a ver com a relação, provavelmente com a figura de identificação que se teve ou não [...], mãe possessiva, ausência de pai; neste rapaz teve claramente a ver com a mãe [...] possessiva [...], a ausência do pai, que não foi física, mas foi um pai ausente da relação. Fez a orientação desde muito cedo, não teve uma figura masculina para se poder identificar e por uma necessidade, provavelmente, de uma outra ancoragem, é a figura da mãe que ele procura.

Ainda dentro desta abordagem, e utilizando a mesma gramática de leitura - a necessidade de papéis de género rígidos -, justificou-se o facto de se considerar uma maior existência de pessoas homossexuais, devido ao facto de "cada vez mais a identificação [com o progenitor do mesmo sexo] ser mais rara".

${ }_{12}$ Refira-se que este modelo foi desenvolvido pelo psicanalista norte-americano Sandor Rado, em 1940. 
Esta leitura da necessidade de modelar papéis de género rígidos para a construção de uma identidade saudável (que por sua vez deverá ser constituída por igual rigidez) permite, neste caso, regular duplamente a ordem social fundada na dicotomização dos géneros: patologiza uma forma de sentir (a afectividade homossexual) e considera que este "desvio" é, por seu turno, consequência de um "desvio" inicial protagonizado pelos progenitores, o que se traduziria num processo de desvio em escalada. É assim que, no primeiro exemplo, a presença de uma mãe dominadora representa uma violação ao papel reservado às mulheres que, também no exercício da maternidade, se deverão manter submissas e ternas; em contrapartida, o papel reservado ao pai, de exercício e representação da autoridade, é, também aqui, transgredido, pela ausência deste.

\subsubsection{Uma falha no processo de desenvolvimento}

Outra leitura enquadrada pelo modelo psicanalítico foi a associação da homossexualidade a um tipo de estrutura de personalidade: uma personalidade narcísica ou, ainda, uma estruturação paranóide ou borderline da personalidade que, "pelo sofrimento que provoca, encontra a sua expressão através da homossexualidade":

É um problema da estrutura da personalidade, do desenvolvimento e maturidade da personalidade.

muitos movimentos de projecção [associados à homossexualidade] e uma grande rigidez [...], uma maior dificuldade que andará ali à volta daquilo a que chamaria uma estrutura de tipo "borderline", "narcísica"

[a homossexualidade é] uma falha narcísica

"[A psicóloga] explicou-me que havia um caminho, que [ou] nós evoluíamos ou ficávamos na homossexualidade”, afirmou um cliente. Um entendimento da afectividade homossexual como uma paragem no processo de desenvolvimento, ao desvalorizar o sentimento, instala mal-estar no sujeito, levando-o a uma procura incessante de transformação e criando um contexto para intervenção.

Por sua vez, esta "estruturação da personalidade" em falha foi considerada responsável pelo que se defendeu ser uma maior dificuldade em estabelecer relacionamentos afectivos com continuidade, entendimento que corresponde a um discurso que faz equivaler uma boa integração da sexualidade a relações "duradouras estáveis e permanentes". Assim, a existência de relacio- 
namentos vários e pouco duradouros foi equacionada pelos clínicos como uma incapacidade afectiva, quando não sintoma de patologia, ao passo que os clientes a referiram como uma preferência, defendendo múltiplas formas de viver relações afectivas, independentemente da orientação sexual.

Uma posição que lê a preferência por relações ocasionais e a falta de interesse em perspectivar relações duradouras como uma incapacidade poderá estar associada a uma dificuldade em aceitar padrões de vida menos normativos, tanto mais que existe, neste caso, um duplo estigma - o da homossexualidade e o da promiscuidade - e ainda o preconceito de que homossexualidade e promiscuidade se relacionam, como, de resto, foi possível observar nos discursos dos clínicos.

\subsubsection{Uma aprendizagem desadequada}

A homossexualidade foi também interpretada como resultado de uma aprendizagem e explicada pelas teorias da aprendizagem: com a insatisfação, no caso da mulher, do relacionamento com homens; com um encontro casual que foi gratificante e que, pela lei do efeito, se procura repetir; com a influência da publicidade e da comunicação social - considerando-se que alguns slogans tinham uma função sedutora e, por isso, prejudicial, por promoverem a homossexualidade:

também tem a ver com o modo como a história e a cultura marcaram negativamente a sexualidade da mulher, quer dizer, a mulher, ao longo de tantos anos, aprendeu mal a viver a sexualidade e, depois, tem uma má aprendizagem com os homens (alguns homens) e fica tão marcada que mais facilmente se orienta a viver com uma mulher

é possível numa sociedade urbana uma mulher destas [mulheres com grandes sentimentos de agressividade contra os homens] ir a um bar onde elas [mulheres homossexuais] se encontram, e ter uma relação [...] quase recreacional que as faz voltar a gostarem um pouco mais delas

também se pode explicar [a homossexualidade] como um condicionamento, houve, por exemplo, uma experiência homossexual que foi gratificante por acaso e depois manteve-se esse padrão, como qualquer adição

outra coisa são os espectáculos que são tão badalados e tão valorizados e tão mediatizados, isso pode alterar a orientação nos jovens, não alterar no sentido cultural [...] porque podem usar um comportamento que é moda, porque é falado, porque é provocatório, porque é anti-qualquer coisa, e no fundo estão a ir um pouco contra eles próprios 
o anúncio das coisas da SIDA mostrava a adolescente e mostrava dois adolescentes rapazes, em que se via claramente o que havia ali, e eram adolescentes, até me questionei um bocado

Todas estas interpretações partem do princípio de que existe apenas uma aprendizagem adequada da sexualidade e de que, no caso da homossexualidade, essa aprendizagem seria feita de uma forma desajustada. Foi esta leitura que justificou, e porventura justifica, intervenções terapêuticas de índole comportamental, de que são exemplo as abaixo descritas:

O médico às tantas propôs-me fazer a terapia comportamental com reflexos condicionados, mostrando-me fotografias de homens e mulheres nuas. De seguida levava electrochoques - já lá vão vinte e tal anos, eu tinha cerca de 20 anos, neste momento tenho 48 [1978].

Nos anos 1980, no meu serviço [...] vi uma coisa aversiva para tentar recondicionar ou descondicionar [...] o caso de uma freira, que era lésbica e se tinha uma coisa que a punha louca eram as mamas!... e então o tratamento para fazer o descondicionamento [...] mostravam-lhe uns cartões - ela detestava fezes - a saírem fezes pelos mamilos [...] fazia parte de uma técnica, obviamente, muito corrente, não tinha estímulos eléctricos, mas tinha outro tipo de estímulos... de fantasia.

Segundo os testemunhos dos clínicos e clientes participantes nos grupos de discussão estas técnicas aversivas já não são praticamente utilizadas, porque, como disseram alguns terapeutas, os seus resultados não corresponderam aos objectivos: se, nalguns casos, podia observar-se um aumento de comportamentos heterossexuais, a conversão da orientação homossexual do cliente em heterossexual não era conseguida, pois, apesar de tudo, os comportamentos homossexuais mantinham-se. Veja-se, a título de exemplo, a transcrição seguinte do discurso de um terapeuta acerca da avaliação de uma terapia aversiva:

Eu continuo a ver alguns desses homens [que fizeram o "tratamento" com técnicas aversivas]. A um deles perguntei-lhe "então e aquele tratamento que fizemos?", ele disse-me assim "Ah! Olhe, você acha que não teve efeito nenhum. Eu devo dizer-lhe, que durante aí uns dois ou três anos, todas as mulheres que me apareciam à frente aquilo ia tudo raso - mas nunca deixei de gostar de homens."

Todavia, paradoxalmente, o uso de intervenções comportamentais não deixou de ser defendido para "casos em que a homossexualidade não fosse considerada a orientação dominante", casos de pessoas "que tenham 
uma motivação muito forte para acabar com um tipo de homossexualidade ou de comportamento homossexual e que sejam heterossexuais dominantes":

Recordo-me pelo menos [de] dois [homens] que vieram pedir ajuda exactamente para esse problema [de comportamentos homossexuais]. É o caso de um homem casado [...], uma pessoa diferenciada, mas que tinha comportamentos homossexuais, do tipo do homossexual envergonhado que vai aos urinóis, e que engata nos urinóis etc., e a determinada altura a mulher descobre e diz-lhe: "ou acabas com isso ou o casamento acaba”. E é nessa altura que ele vem pedir ajuda e portanto aí fez-se o tratamento. De resto, esses dois casos [...] foram tratados, ele e um outro caso semelhante a este foram tratados com a técnica que nós designamos como dessensibilização encoberta

Parece esboçar-se, assim, uma diferença de interpretação entre o que se considera ser homossexualidade exclusiva ("não tratável", antes objecto de aceitação) e esse "certo tipo de homossexualidade", apanágio de pessoas com um comportamento heterossexual considerado dominante. Esta posição faz pensar na valorização que é feita de uma orientação exclusiva, facto que, aliás, foi comentado por uma terapeuta:

nós acabamos por fazer uma coisa, já repararam, que é assim, é quase como se achássemos que tanto faz, mas tem é que se definir

Por outro lado, a defesa de intervenções comportamentais para as situações referidas revela uma crença, por parte do terapeuta, de uma maior possibilidade de mudança, quando os comportamentos homossexuais coexistem com comportamentos heterossexuais. Aqui, a homossexualidade foi interpretada como uma variável contínua e definida a partir de comportamentos sexuais: no eixo homossexual/heterossexual, uma maior proximidade da heterossexualidade implica uma maior possibilidade de reversão.

Durante a discussão, na reflexão em torno desta questão, o único factor questionado foi a orientação sexual e foi esse factor, como se observa na transcrição do discurso, que constituiu o critério de "tratamento". Todavia, o que aqui poderia ter sido problematizado era a necessidade de controlo de outra norma: a da exclusividade de relacionamentos afectivo-sexuais. A omissão desta problematização poderá denunciar uma hierarquia de "factores desviantes", onde a homossexualidade será considerada mais desviante do que a não exclusividade. 


\subsubsection{Uma determinação biológica}

A homossexualidade explicada com base no modelo biológico também surgiu na discussão. Contudo, em face de tantas teorias biológicas já construídas, saliente-se que os terapeutas denunciaram a vulnerabilidade dessas teorias, trazendo para o debate os factores biológicos apenas quando em simultâneo com outros:

A tese hormonal, a mim, faz-me sentido como estando sempre presente [...], acho que há possibilidade de ela surgir ou não, e isso aí é muito cultural. As hormonas como factor predisponente e as questões culturais de tolerância social como factores desencadeantes.

[Há] factores genéticos, de imprinting, hormonais e também de aprendizagem. E quantas vezes os factores de aprendizagem não estão a mascarar factores biológicos que seriam determinantes, se a vida não tivesse condicionado a orientação de outro modo

Temos que pensar nos estudos biológicos de formação do cérebro durante a gravidez pelas hormonas sexuais, não é? Há pessoas que têm coisas dessas publicadas que poderão eventualmente explicar algumas situações onde a coisa é mesmo muito definida [...] agora, eu, pessoalmente, acredito que pode haver experiências precoces da primeira infância que passam a ser determinantes e depois toda a aprendizagem noutras situações de vida.

Pode inferir-se daqui que nenhuma das teorias ancoradas na biologia ganhou uma expressão significativa - o próprio facto de a replicação de todos estes estudos nada ter provado de conclusivo permite refutar qualquer uma delas.

Observe-se, a este propósito, uma afirmação que merece uma especial reflexão, sobretudo se pensarmos nos riscos do aproveitamento político: "se se descobrir que a homossexualidade é um cromossoma, então (...) a homossexualidade será uma doença”, afirmou uma terapeuta. O facto de a homossexualidade poder eventualmente ser determinada geneticamente não implica que ela tenha configurações patológicas. Ora o que se verifica aqui é uma relação causal, resultado de preconceito (a noção de que a homossexualidade é algo negativo). Aproveita-se, assim, a questão genética para reforçar a ideologia de doença: acha-se que até geneticamente há uma norma e que as possibilidades de mutações diferentes dessa norma significam, porque desvios, uma patologia. Será, afinal, transformar uma norma puramente estatística numa norma que organiza uma ordem social. 


\section{Uma cortina menos visível: $O$ heterossexismo'3}

Interpretar o mal-estar dos clientes como um pedido de mudança da sua homossexualidade e negar a homossexualidade dos clientes são posições que merecem ser aqui destacadas, pelo que revelam de heterossexismo.

Comece-se por reflectir sobre o facto de alguns clínicos, falando dos motivos que levaram os clientes às consultas, apontarem uma mudança entre o que se passava nas décadas de 1970 e 1980 e a situação actual, relativamente à interpretação da homossexualidade:

Em 1970 devo ter visto vinte e tal homossexuais masculinos e todos eles desejavam a mudança para a heterossexualidade [...]; a partir dos anos 80 raramente tenho alguém que venha pedir a reversão da orientação, há mais de dez anos que não tenho ninguém a pedir a reversão.

É significativa a influência do terapeuta nas decisões do cliente, como refere Davison (1991), ao considerar que os terapeutas parecem ser capazes de fazer os clientes desejarem o que está disponível e o que eles acham que os clientes deveriam desejar. ${ }^{14}$ Para Davison, os problemas psicológicos são, na maior parte, construções dos clínicos, que assim orientam a sua interpretação numa direcção: a homossexualidade é vista como a fonte do problema e, consequentemente, o pedido é lido como desejo de mudança da orientação sexual. Um excelente exemplo ilustrativo deste processo é a seguinte fala de um cliente:

O médico entendia que eu devia deixar de ser homossexual, uma vez que não me sentia bem naquele papel, e propôs-me fazer a terapia comportamental. $\mathrm{Na}$ altura eu sentia que era aprovado e que ele me aceitava, mas [...] havia sempre a perspectiva de ele me querer mudar, até porque eu não sabia bem, sentia-me tão mal, tão mal na pele de homossexual [...] que ele se calhar [...] achou que era melhor assim, fazer a terapia com aqueles choques eléctricos. Nessa altura estava muito em voga.

${ }_{13}$ Heterossexismo foi um termo proposto por Stephen Morin em 1977, significando as crenças e atitudes que não atribuem o mesmo valor aos estilos de vida entre pessoas do mesmo sexo e entre pessoas de sexos diferentes. De uma forma geral, o termo é utilizado para referenciar o sistema ideológico que nega, denigre e estigmatiza qualquer forma de comportamento, identidade, relacionamento ou comunidade não heterossexual. É, ainda, usado para caracterizar os preconceitos heterossexuais contra homossexuais bem como os comportamentos baseados nestes preconceitos - sugere paralelismo entre o sentimento anti-gay e outras formas de preconceito como o racismo, o antisemitismo ou o sexismo. Um dos efeitos pragmáticos do heterossexismo é a necessidade de indivíduos homossexuais passarem por heterossexuais (Herek, 1996).

${ }_{14} \mathrm{O}$ papel dos factores subjectivos na percepção e na resolução de problemas tem sido reconhecido, e demonstrado em psicologia experimental, desde os trabalhos de Wundt, e confirmado na psicologia cognitiva (Bruner e Goodman, 1974) e na ciência cognitiva actual (Neisser, 1976). Da mesma forma, Kuhn (1962), na sua análise epistemológica, compara explicitamente os paradigmas em ciência com viés perceptivos, que afectam a forma como os dados são recolhidos e mesmo definidos. 
O que levou o cliente à consulta foi a ansiedade e o profundo desconforto consigo próprio e com os outros; todavia, como ele próprio acrescenta, a proposta de alteração da orientação sexual surgiu por parte do terapeuta, não dele. O que aqui encontramos é a transformação do desejo na percepção do desejo do outro: se, por parte do cliente, existe a percepção do desejo do terapeuta e uma tentativa de corresponder a esse desejo, verifica-se igualmente, por parte do terapeuta, a tentativa de corresponder ao pedido que ele projectara no cliente. Como num jogo de espelhos, terapeuta e cliente recebem as imagens de si próprios, projectadas no outro. É como se a percepção do terapeuta orientasse o pedido, através da expectativa que ele próprio (terapeuta) cria.

Uma outra estratégia, que pode ser relacionada com o desejo dos clínicos de que o cliente seja heterossexual e que só aparece referida nas falas dos clientes, é a da negação da homossexualidade:

A psiquiatra, a primeira vez que me viu, passados cinco minutos de estar comigo estava-me a dizer que eu não era nada homossexual, que estava deprimida porque $o$ que eu gostava era de homens. Portanto, a minha orientação sexual era heterossexual e não homossexual.

[A terapeuta] veio logo com a conversa da homossexualidade, dizendo que realmente não me via a mim como homossexual, via-me mais como heterossexual, portanto aquela conversa do costume [...] [de] realmente tentar-nos convencer que nós não somos homossexuais, somos mais heterossexuais.

O primeiro médico disse que era uma fase por que eu estava a passar.

[O meu terapeuta disse-me] "ó pá, isso não é nada! Isso não é absolutamente nada! Eu vou-te receitar aqui [...] umas casas de dança e umas pensões e tu vais assim a umas lojas, vais falar às balconistas. Tenta engatar umas...". Depois disse-me "vem daqui a seis meses, vais voltar e vais ver que resultou" [...]. Deu-me dicas para uma possível procura do lado heterossexual.

[O meu terapeuta] disse-me "olhe, em relação a isto não se preocupe, você não tem estrutura de homossexual!" [...] e disse-me mais: "se o seu marido fosse uma pessoa mais meiga... e é isso que você tem que tentar encontrar... se ele for uma pessoa mais meiga, eu estou convencido que essas coisas the passam" [...] e até me disse: "olhe para si, veja-se ao espelho!”. Eu, na altura, tinha cabelo comprido, caracóis e tudo, de maneira que devia ser [heterossexual]... 
Esta estratégia de negação da homossexualidade do cliente (apenas referida pelos clientes), observada quer quando a homossexualidade era o motivo de procura de apoio, quer quando não o era, pode revelar mais do que uma medida terapêutica: na realidade, será a expressão do desejo do clínico. Se essa estratégia revela a dificuldade em lidar com a homossexualidade, ela é ainda um indicador de heterossexismo, no sentido em que genuinamente se aceita que o bem-estar do cliente e a sua adaptação social dependem da orientação heterossexual. Para alguns clientes, e durante um "muito curto prazo" esta negação da homossexualidade foi inicialmente sentida como tendo sido motivo de "alívio", de "descanso", tendo, todavia, sido posteriormente avaliada como "traumatizante", "terrível, terrível, terrível":

[D]isse-me “[...] não se preocupe, você não tem estrutura de homossexual”. A princípio, fiquei muito descansada, respirei fundo [...] no fundo, eu quis ouvir aquilo que ele me disse, aquilo sossegou-me. O que é certo é que a coisa foi piorando, piorando, piorando, piorando [...]. A forma como isto foi aceite, eu acho, para mim, pelo menos, foi profundamente traumatizante. [...] Obviamente que a pessoa depois internaliza a culpa, não é? Começa é a pensar “a culpa é minha”. [...]. Eu estive [...] quase à beira do suicídio [ano de 1988].

À semelhança do que é referido por Liddle (1997) e Rudolph (1989) nos seus estudos, também entre os clientes homossexuais portugueses há um sentimento de que a ignorância e o preconceito dos clínicos relativamente à homossexualidade são os responsáveis pela insatisfação que eles, como clientes, sentem com posições assumidas por alguns terapeutas.

\section{Notas finais}

Podem retirar-se algumas conclusões desta investigação. Os discursos dos clínicos portugueses participantes no estudo assemelham-se àqueles que são referidos em estudos realizados noutros países, entre os quais o Reino Unido (Annesley e Coyle, 1998), a Suíça (Frossard, 2000) e os Estados Unidos da América (Garnets et al., 1981; Graham et al., 1984; Liddle, 1996, 1997).

Também entre os terapeutas portugueses, tal como entre os terapeutas dos estudos enunciados, a homossexualidade ainda surge configurada como um défice, e, embora muitas vezes não seja claramente afirmado, detecta-se essa configuração através da defesa de modelos etiológicos que a consideram o resultado de "uma falha no processo de identificação" ou "uma falha narcísica”, através da veiculação de preconceitos, como, por exemplo, a 
(in)capacidade de envolvimento amoroso das pessoas homossexuais, particularmente dos homossexuais masculinos, ou através da negação da orientação homo-erótica: "é uma fase", "você não tem estrutura de homossexual [...] olhe para si, veja-se ao espelho".

O facto de o modelo patológico da homossexualidade ter tido expressividade nos discursos de alguns clínicos é um indicador de que entre a comunidade terapêutica portuguesa ainda existem preconceitos que podem conduzir a terapias desajustadas e a enviesamentos na avaliação dos clientes. Este entendimento, entre outros, explica que os clientes tenham detectado no processo terapêutico uma preocupação com a procura da génese da sua homossexualidade, ou que se tenham sentido objecto de alguma condenação, ainda que nem sempre de uma forma explícita.

$\mathrm{Na}$ análise aos discursos dos clientes, a presença do heterossexismo dos terapeutas tornou-se clara - negar os sentimentos homo-eróticos, como alguns terapeutas fizeram, é construir como padrão ideal a heterossexualidade e devolver ao outro esse padrão. Assim, uma identificação importante foi a detecção no discurso dos clínicos não tanto de homofobia, mas sobretudo de heterossexismo, o que é mais difícil de combater e erradicar, porquanto aí, ao poder confundir-se com tolerância - e tolerância comporta na sua génese desigualdade, já que perpetua escalas de poder -, é menos visível a localização do preconceito.

É de notar que a interpretação da homossexualidade como um défice não é obstáculo a que os terapeutas se preocupem genuinamente com o bem-estar do cliente e tentem auxiliá-lo a viver com a sua orientação sexual, sendo muitas as avaliações positivas feitas pelos clientes, da intervenção terapêutica. No entanto, deve questionar-se que tipo de impacto terá a intervenção de um terapeuta que, ainda que considerando a homossexualidade um défice e afirmando que as pessoas homossexuais têm o direito de viver bem com esse défice, interpreta o sentimento de bem-estar do cliente homossexual como uma atitude de defesa.

Este duplo padrão poderá provocar no cliente uma posição de "double bind" (Watzlawick, 1967), enclausurando-o numa situação paradoxal e circular do tipo "ajudo-te a ser feliz, embora a tua condição de homossexual te impeça de o seres". Assim, o cliente procurará essa ajuda recorrentemente, estabelecendo uma relação de causa/efeito entre o seu mal-estar e a sua orientação sexual; a validação (quando não a atribuição) pelo terapeuta deste tipo de raciocínio pode centrar de tal forma o foco de intervenção na homossexualidade (na sua génese), que o cliente se detenha, em cumplicidade com o terapeuta, nesse mesmo foco e dele não saia nunca - porque em torno desse foco incessantemente se moverá. 
A análise aqui apresentada reforça a consciência do muito que ainda há por fazer no combate à discriminação, na defesa do direito à plena vivência dos afectos e da sexualidade em toda a sua plasticidade; do muito que ainda há por fazer, retomando o poema de Jorge de Sena citado em epígrafe, na promoção da dignidade humana. Para que finalmente se possa, como se lê no mesmo poema, "amar o [...] semelhante com o que ele [tem] de único/de insólito, de livre, de diferente”.

\section{Referências bibliográficas}

Annesley, Phyllis; Coyle, Adrian (1998), "Dykes and Psychs: Lesbian Women's Experience of Clinical Psychological Services", Changes: An International Journal of Psychology and Psychoterapy, 16, 247-258.

Bruner, Jerome; Goodman, Cecile (1974), "Value and Need as Organizing Factors in Perception", Journal of Personality, 16, 69-77.

Cass, Vivienne (1984), "Homosexual Identity Formation: Testing a Theoretical Model", The Journal of Sex Research, 20(2), 143-167.

Coleman, Eli (1988), "Assessment of Sexual Orientation", in E. Coleman (org.), Integrated Identity for Gay Men and Lesbians. New York: Harrington Park Press, 9-24.

Davison, Gerald C. (1991), "Constructionism and Morality in Therapy for Homosexuality”, in John Gonsiorek; Janes Weinrich (orgs.), Homosexuality: Research Implications for Public Policy. Newbury Park: Sage Publications,137-148.

Frossard, Jacqueline (2000), Lesbische Franen in der Psychoterapie. Universidade de Basileia (diss. de doutoramento).

Garnets, Linda et al. (1991), "Issues in Psychotherapy with Lesbians and Gay Men", American Psychologist, 46, 964-972.

Graham, Dee et al. (1984), "Therapist's Needs for Training in Counselling Lesbians and Gay Men. Professional Psychology", Research and Practice, 15(4), 290-297.

Herek, Gregory (1996), "Heterosexism and Homophobia", in Robert Cabaj; Terry Stein (orgs.), Textbook of Homosexuality and Mental Health. Washington DC: American Psychiatric Press, 101-113.

Hill, Clara; Thompson, B. J.; Williams, E. N. (1997), "A Guide to Conducting Consensual Qualitative Research”, The Counseling Psychologist, 25(4), 517-572.

Ibañez, J. (1992), Más allá de la sociología. Madrid: Siglo XXI de España Editores [1979]. Klein, Fritz; Sepekoff, Barry; Wolff, Timothy (1985), "Sexual Orientation: A MultiVariate Dynamic Process", Journal of Homosexuality, 11(1-2), 35-49.

Krueger, Richard (1988), Focus Groups: A Practical Guide for Applied Research. Beverly Hills, California: Sage Publications.

Kuhn, Thomas (1962), The Structure of Scientific Revolutions. Chicago: University of Chicago Press. 
Lehne, Gregory (1976), "Homophobia Among Men”, in Deborah Davis; Robert Brannon (orgs.), The Forty-Nine Percent Majority: The Male Sex Role. Reading, MA: Addison-Wesley, 66-68.

Liddle, Becky (1996), “Therapist Sexual Orientation, Gender, and Counselling Practices as They Relate to Ratings of Helpfulness by Gay and Lesbian Clients", Journal of Counselling Psychology, 43(4), 394-401.

Liddle, Becky (1997), "Gay and Lesbians Client's Selection as Therapists and Utilization of Therapy”, Psychotherapy, 34(1), 11-18.

Logan, Colleen (1996), "Homophobia? No, Homoprejudice", Journal of Homosexuality, 31(3), 31-53.

Moita, Gabriela (2001), Discursos sobre a homossexualidade no contexto clínico: A homossexualidade de dois lados do espelho. Instituto de Ciências Biomédicas de Abel Salazar da Universidade de Porto (diss. de doutoramento).

McHenry, Sherry; Johnson, Jackie (1993), "Homophobia in the Therapist and Gay or Lesbian Client: Conscious and Unconscious Collusions in Self-Hate”, Psychotherapy, 30, 141-151.

Morin, Stephen (1977), "Heterossexual Bias in Psychological Research on Lesbianism and Male Homosexuality", American Psychologist, 32, 629-637.

Neisser, Ulric (1976), Cognition and Reality. San Francisco: Freeman.

Rubio, Sonia (1996), Processo de desarollo de la identidad homosexual. Universidade de Salamanca (diss. de doutoramento).

Rudolph, James (1989), "Effects of a Workshop on Mental Health Practioners's Attitudes toward Homosexuality and Counseling Effectiveness", Journal of Counseling E Development, 68, 81-85.

Smith, Kenneth (1971), "Homophobia: A Tentative Personality Profile”, Psychological Reports, 29, 1091-1094.

Stiles, William (1993), "Quality Control in Qualitative Research”, Clinical Psychology Review, 13, 593-618.

Valles, Miguel (1977), Tecnicas cualitativas de investigación social: reflexión metodológica e prática profesional. Madrid: Editorial Síntesis.

Weinberg, George (1972), Society and the Healthy Homosexual. New York: Oxford UP. Watzlawick, Paul (1967), Pragmatics of Human Communication. New York: Norton. 